\title{
CONTEXTOS E SITUAÇÕES DE APRENDIZAGEM DE TREINADORES DE HANDEBOL EM ÂMBITO ESCOLAR
}

SCHOOL HANDBALL COACHES' LEARNING CONTEXTS AND SITUATIONS

CONTEXTOS Y SITUACIONES DE APRENDIZAJE DE ENTRENADORES DE BALONMANO EN EL ÁMBITO ESCOLAR

Felipe Modolo*, Mayara Gonçalves Madeira*, Walmir Romário dos Santos*, Marcos de Paula D’Almeida*, Rafael Pombo Menezes*

Palavras chave:

Treinador.

Esportes.

Aprendizagem.

Conhecimento

\begin{abstract}
Resumo: O objetivo desta pesquisa foi analisar a formação de treinadores de handebol de âmbito escolar, bem como identificar os contextos e situações de aprendizagem preferidos por eles. Para isso foram entrevistados 11 treinadores de âmbito escolar de um município do Estado de São Paulo. O instrumento de entrevista semiestruturada abrangeu duas questões principais: uma relacionada à formação acadêmica (graduação e pós-graduação) e outra referente aos diferentes contextos de aprendizagem. Os entrevistados relataram que a graduação cumpre um importante papel na formação, porém insuficiente para o domínio dos conteúdos específicos inerentes ao seu contexto de atuação. Considerando os contextos de aprendizagem os treinadores apontam preferência pelas fontes provenientes do contexto informal (como as experiências como atleta, as conversas com outros treinadores e os materiais disponíveis na internet), ao passo que apontam o contexto não formal como pouco relevante para a atuação.
\end{abstract}

Keywords:

Coaching.

Sports.

Learning.

Knowledge.

\begin{abstract}
This work analyzes school handball coaches' academic background and identifies their preferred learning contexts and situations. Eleven school coaches from a city in the Brazilian State of São Paulo were interviewed. The semi-structured interview included two main questions: one related to college education (undergraduate and graduate studies) and another one related to different learning contexts. Interviewees reported that undergraduate students play an important role in their training, but were not enough to master the specific knowledge related to their work context. Considering the learning contexts, coaches preferred sources coming from informal contexts - such as their experiences as athletes, conversations with other coaches, and material available online. Coaches also pointed that non-formal contexts were not very relevant to their work.
\end{abstract}

Palabras clave: Entrenador. Deportes. Aprendizaje. Conocimiento.
Resumen: El objetivo de esta investigación fue analizar la formación de entrenadores escolares de balonmano en el ámbito escolar e identificar los contextos y situaciones de aprendizaje preferidos. Para ello fueron entrevistados 11 entrenadores de ámbito escolar de un municipio de la ciudad de São Paulo. El instrumento de entrevista semiestructurada cubrió dos cuestiones principales: la formación académica (grado y postgrado) y los diferentes contextos de aprendizaje. Los entrevistados relataron que la graduación juega un papel importante en la formación, aunque insuficiente para el dominio de los contenidos específicos de su contexto profesional. Teniendo en cuenta los contextos de aprendizaje, los entrenadores manifiestan preferencia por fuentes provenientes del contexto informal (por ejemplo, la experiencia como atleta, conversaciones con otros entrenadores y los materiales disponibles en internet), mientras que señalan el contexto no formal como poco relevante para la actuación profesional.
*Universidade de São Paulo (USP) Ribeirão Preto, SP, Brasil. E-mail: femodolo@usp.br, mayara. madeira@usp.br,walmir@usp.br. marcos_dalmeida@hotmail.com, rafaelpombo@usp.br

Recebido em: 07-03-2017 Aprovado em: 22-08-2017

DOI: http://dx.doi.org/10.22456/1982-8918.71699 (c) (1) (8) Licence 


\section{INTRODUÇÃO}

No Brasil a Lei Federal 9615/1998, art. 3ㅜㅡ, estabelece as seguintes manifestações esportivas: a) esporte educacional; b) esporte de participação; c) esporte de rendimento; e d) esporte de formação' (BRASIL, 1998a). Já a Lei Federal 9696/1998 (BRASIL, 1998b) exige que o treinador esportivo deva ser registrado no Conselho Regional de Educação Física (CREF), para o qual a graduação em Educação Física constitui-se como um pré-requisito² ${ }^{\text {(BRASIL, }}$ 1998b; MILISTETD et al., 2014).

Pautando-se nas especificidades das distintas carreiras profissionais, há dois currículos de graduação em Educação Física: Bacharelado e Licenciatura (BRASIL, 2002; MILISTETD et al., 2014; 2015). De acordo com a Resolução CNE/CP n¹/2002 (BRASIL, 2002) a Licenciatura está voltada à formação de professores para o âmbito escolar, enquanto o Bacharelado referese à formação de profissionais que atuarão em outras áreas, como a de treinador esportivo.

Devido à complexidade do contexto no qual o treinador está inserido (BOWES; JONES, 2006), não é possível aprofundar durante a graduação os conhecimentos necessários para se tornar um treinador esportivo (MILISTETD et al., 2014), mesmo considerando o âmbito escolar. Nesse sentido, ser treinador esportivo vai além de possuir o conhecimento específico de um esporte (GALATTI et al., 2016), mas de compreender a complexidade do contexto cultural e social no qual seu trabalho se insere e, assim, pensar o ensino de um determinado esporte de maneira holística e não somente pragmática e/ou tecnicista (JONES, 2006; CASSIDY; JONES; POTRAC, 2009).

De acordo com Nelson, Cushion e Potrac (2006) os treinadores podem aceder a três diferentes contextos de aprendizagem. $O$ contexto formal é caracterizado por situações em que é necessário passar por algum processo de seleção antes de iniciar um curso com currículo estruturado e uma certificação ao final. O contexto não formal é semelhante ao formal, porém é direcionado para uma população específica com temas de interesse deste grupo. Já o contexto informal engloba todas as situações em que o indivíduo busca determinado conhecimento sem estar necessariamente vinculado a uma certificação, bem como se relaciona com a experiência e a reflexão prática.

Diante desses diferentes contextos, os treinadores podem optar por diferentes situações de aprendizagem para buscar os conhecimentos que julgam interessantes ao seu ambiente de treinamento. Lemyre, Trudel e Durand-Bush (2007), em um estudo com treinadores de equipes jovens de hóquei no gelo, beisebol e futebol, apontaram que os programas formais de formação, embora não obrigatórios no âmbito investigado, são importantes principalmente no primeiro ano como treinador principal.

Tais situações de aprendizagem relacionam-se às formas nas quais o treinador buscará o conhecimento, enquanto o contexto de aprendizagem está relacionado ao tipo de acesso a esse conhecimento. As situações de aprendizagem podem ser caracterizadas como mediada, direta e interna (WERTHNER; TRUDEL, 2006). As situações de aprendizagem mediada constituem-se em um importante meio para a formação do treinador esportivo (WERTHNER; TRUDEL, 2006; CUNHA; ESTRIGA; BATISTA, 2014; STOSZKOWSKI; COLLINS, 2016;

10 item "d" foi alterado pela Lei Federal 13.155/2015, Art.38

2 Salvo exceções previstas na Lei 9696/98, artigo 2º , parágrafo III, assim apresentado: "os que, até a data do início da vigência desta Lei, tenham comprovadamente exercido atividades próprias dos Profissionais de Educação Física, nos termos a serem estabelecidos pelo 
TRUDEL; GILBERT; RODRIGUE, 2016). Deve-se considerar a mediação não como uma simples relação de transmissão, na qual os mediadores detêm o conhecimento e vão transmitilo aos aprendizes, mas como um processo influenciado pelas situações sociais advindas das experiências ao longo da vida (JONES, 2006; MILISTETD et al., 2015). A aprendizagem direta configura as situações em que 0 aprendiz busca um conhecimento específico sem a necessidade de um mediador e relaciona-se ao que é de seu interesse (WERTHNER; TRUDEL, 2006; CUNHA; ESTRIGA; BATISTA, 2014). A aprendizagem interna é caracterizada por uma reflexão acerca do conhecimento construído ao longo de sua formação como treinador (WERTHNER; TRUDEL, 2006; CUNHA; ESTRIGA; BATISTA, 2014).

Entendendo, portanto, que a atuação do treinador se dá em um ambiente complexo, sob a influência de diferentes contextos e situações que requerem o desenvolvimento de diferentes competências, torna-se relevante compreender como se dá o processo de formação deste. Volta-se atenção especial aos treinadores de equipes escolares de handebol, escolha essa justificada pela escassez de estudos que investiguem esse ambiente.

Ademais, investigar treinadores que atuam em âmbito escolar, com inserção em diferentes ambientes competitivos, pode fornecer um panorama sobre seu processo de formação, em especial sobre as fontes de aprendizagem que consideram mais relevantes para o aprofundamento no conhecimento específico do handebol. Sendo assim, constituem-se como perguntas centrais desta pesquisa: qual é o papel da graduação para a formação dos treinadores e quais são as fontes de aprendizagem preferidas por eles?

O objetivo desta pesquisa foi, portanto, analisar a formação de treinadores de handebol de âmbito escolar de um município do Estado de São Paulo, assim como identificar as situações e os contextos de aprendizagem preferidos por eles.

\section{MÉTODO}

\subsection{Sujeitos}

A amostra foi composta por onze treinadores de handebol de âmbito escolar de uma cidade do interior do Estado de São Paulo. Todos os entrevistados são graduados em Educação Física, trabalham com turmas de treinamento em handebol na escola (no contraturno escolar) e disputaram uma liga municipal composta por 14 equipes (quando a pesquisa foi realizada). Dos 14 possíveis treinadores, onze concordaram em participar da pesquisa e suas características estão apresentadas no Quadro 1.

Quadro 1 - Características dos treinadores entrevistados nesta pesquisa

\begin{tabular}{|c|c|c|c|c|}
\hline Treinador & Idade & $\begin{array}{c}\text { Tempo de } \\
\text { graduação }\end{array}$ & $\begin{array}{c}\text { Tempo médio de atuação } \\
\text { (âmbito escolar) }\end{array}$ & Pós-graduação \\
\hline S1 & 38 & 1 & 7 & Sim \\
\hline S2 & 52 & 27 & 27 & Não \\
\hline S3 & 27 & 6 & 8 & Sim \\
\hline S4 & 27 & 6 & 6 & Não \\
\hline S5 & 48 & 28 & 9 & Sim \\
\hline S6 & 59 & 40 & 20 & Sim \\
\hline
\end{tabular}


Continuação do quadro $1 .$.

\begin{tabular}{|c|c|c|c|c|}
\hline S7 & 52 & 28 & 5 & Sim \\
\hline S8 & 32 & 9 & 4 & Em andamento \\
\hline S9 & 51 & 29 & 14 & Não \\
\hline S10 & 44 & 21 & 22 & Sim \\
\hline S11 & 43 & 21 & 15 & Sim \\
\hline Média (sd) & $43( \pm 10,8)$ & $19,6( \pm 12,4)$ & $12,5( \pm 7,7)$ & 7 sim \\
& & & & 3 não \\
& & & em andamento \\
\hline
\end{tabular}

Fonte: os autores

\subsection{Procedimentos para entrevista}

Os treinadores foram contatados via telefone e/ou e-mail, para verificar a disponibilidade e o interesse em participar desta pesquisa. Após o aceite, as entrevistas foram agendadas em locais e horários que não concorriam com suas atividades profissionais, de modo a direcionar sua atenção para as questões abordadas. Todas as entrevistas foram realizadas pessoalmente e os áudios foram gravados na íntegra (formato MP3). Todos assinaram um Termo de Consentimento Livre e Esclarecido aprovado pelo Comitê de Ética em Pesquisa institucional, recebendo uma via desse no momento da entrevista.

Esta pesquisa foi desenvolvida partindo de uma abordagem qualitativa, pois a perspectiva dos treinadores envolvidos e a reflexão do pesquisador constituíram-se como aspectos fundamentais para o seu desenvolvimento (FLICK, 2009; THOMAS; NELSON; SILVERMAN, 2012). Como método de produção de dados optou-se pela entrevista semiestruturada, justificada pela liberdade do entrevistado manifestar sua opinião sobre dada temática e pelo fato do entrevistador poder elencar novas prerrogativas a partir dessas opiniões (MARCONI; LAKATOS, 2011).

Apresentaram-se, portanto, como questões norteadoras do roteiro de entrevista: 1) "Você acredita que sua formação acadêmica (graduação e/ou pós-graduação) foi suficiente para dominar os conteúdos específicos que utiliza como treinador? Por quê?"; 2) "Como você reúne os conhecimentos específicos do handebol atualmente?"

\subsection{Análise das entrevistas}

Após a transcrição na íntegra dos áudios das entrevistas, os discursos foram tabulados e analisados com base no método do Discurso do Sujeito Coletivo (DSC), que considera a discursividade característica do pensamento coletivo, representando o pensamento de uma coletividade sobre um determinado tema a partir de um "discurso-síntese" (LEFÉVRE; LEFÉVRE, 2012).

Foram identificadas e construídas as seguintes figuras metodológicas: expressõeschave (ECH: trechos literais contínuos ou descontínuos do discurso que revelam a essência da entrevista); ideias centrais (IC: expressões que descrevem de maneira sucinta, precisa e fidedigna o significado dos discursos de cada grupo de ECH); e o próprio DSC (discurso-síntese redigido em primeira pessoa, contendo as ECH agrupadas em cada IC). 
A partir da construção dos DSC, que representam um pensamento coletivo e/ou do universo dos sujeitos pesquisados sobre a temática, foram consideradas as diferenças e similaridades de concepções.

\section{RESULTADOS E DISCUSSÃO}

Os treinadores manifestaram de forma unânime que o contexto de aprendizagem formal, representado pela graduação e/ou pós-graduação, não foi suficiente para o domínio das questões específicas do handebol, conforme apresentado nos trechos 1 e 2 do DSC1 (proveniente da IC-1: "Formação acadêmica"):

Trecho 1: "Acho que a formação acadêmica em si para um treinador é

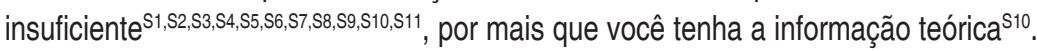
Ela te dá uma base, um ponto de partidast,s9,510".

Trecho 2: "Na minha época a maioria se formou pra ser professor de escola, a gente tinha pouca coisa esportiva e mais a parte educacional. Os pontos fortes foram a parte pedagógica e recreaçãos5. Agora teve a diferenciação [licenciatura e bacharelado] $]^{5 n}$.

Diferentes autores têm apontado que o conhecimento transmitido na graduação é insuficiente para ascender a um nível de performance como treinador esportivo de um esporte (LEMYRE; TRUDEL; DURAND-BUSH, 2007; MILISTETD et al., 2014; MILISTETD et al., 2015; STOSZKOWSKI; COLLINS, 2016), opinião também compartilhada pelos treinadores no DSC1.

Para Milistetd et al. (2014), ao longo da formação acadêmica não há tempo para aprofundar os conhecimentos necessários para se tornar um treinador esportivo, neste caso, no âmbito escolar. Tal aspecto é reforçado pela prerrogativa da formação generalista em Educação Física, regulamentada pela Resolução CNE/CES 7/2004³. Nos trechos 1 e 2 do DSC1 os treinadores relataram tal perspectiva de formação destacando que a graduação fomenta uma base de conhecimentos. Entendemos que essa base inicial de conhecimentos seja importante para orientar as buscas dos treinadores por aspectos que contemplem sua atuação profissional.

Sendo assim, o contexto retratado sobre o papel da graduação pelos entrevistados aproxima-se dos achados de outras pesquisas (WERTHNER; TRUDEL, 2006; LEMYRE; TRUDEL; DURAND-BUSH, 2007; MILISTETD et al., 2014; MILISTETD et al., 2015; STOSZKOWSKI; COLLINS, 2016; TRUDEL; GILBERT; RODRIGUE, 2016). Entretanto, estes treinadores disputam uma liga local escolar (e algumas competições em âmbito estadual), inserindo-se no contexto de esporte de participação (BRASIL, 1998a), a partir de sua ressignificação, atribuindo o significado e objetivo dos participantes no ambiente escolar (MARQUES, 2015). Percebe-se a partir do DSC1 que, além de existirem competências específicas sobre os conteúdos do handebol que não são abordadas na graduação, há uma lacuna em relação ao enfoque das competições em âmbito escolar: no caso dos treinadores entrevistados, as exigências se aproximam de níveis competitivos mais elevados (com competições disputadas em âmbito estadual, por exemplo).

Apesar do contexto desses treinadores estar alicerçado em uma base escolar, há a premissa de melhorar o desempenho de jogadores e equipes para buscar resultados

30 Art. 4 da referida Resolução aponta que "[...] o curso de graduação em Educação Física deverá assegurar uma formação generalista humanista e crítica, qualificadora da intervenção acadêmico-profissional, fundamentada no rigor científico, na reflexão filosófica e na conduta ética". 
em âmbito estadual e/ou municipal. Esse processo ocorre de maneira diferente do que é enfatizado nas aulas de Educação Física (esporte de participação), verificado no fato de que os treinamentos dessas equipes ocorrem no contraturno escolar, clarificando a diferença entre o que é desenvolvido nas aulas e o que se desenvolve nos treinos, com vistas ao desempenho nas competições escolares.

Abre-se, portanto, uma possibilidade para o debate sobre as características das competições escolares, que poderiam apresentar regulamentos específicos para a participação de todos os inscritos, bem como buscar o maior número de jogos entre as equipes, privilegiando a vivência dos alunos. Outro aspecto importante nesse meio corresponde às reuniões entre os treinadores, que podem viabilizar as trocas de experiências e fomentar mudanças no ambiente de aprendizagem.

Da mesma forma, seria importante verificar se a participação dos treinadores nessas competições influencia, de alguma forma, a sua concepção sobre o papel da graduação em relação ao domínio dos conteúdos específicos do handebol. Destaca-se que há a preocupação, em especial para os antigos cursos de Licenciatura Plena em Educação Física, com a vertente do esporte de participação e educacional (em alusão à Lei Federal 9615/1998), o que se distancia da lógica competitiva da qual participam os entrevistados. Assim sendo, para os objetivos do esporte competitivo, como o nível de rendimento é maior, os treinadores sentem a necessidade de buscar um conhecimento que a graduação, em tese, não conseguiu suprir (trechos 1 e 2 do DSC1).

No trecho 2 os treinadores relataram uma diferença em sua formação acadêmica devido a uma mudança na regulamentação dos cursos de Educação Física no Brasil, estabelecendo duas carreiras distintas: a Licenciatura e o Bacharelado, conforme abordado anteriormente. Entendemos, portanto, que há a necessidade do curso de Bacharelado em Educação Física repensar algumas estratégias específicas no que tange à formação de treinadores, possibilitando o desenvolvimento de suas competências ainda na graduação (MILISTETD et al., 2015). Feu Molina, Ibañez Godoy e Gonzalo Delgado (2010) destacaram a necessidade de investir na formação do treinador esportivo escolar, estabelecendo os conteúdos necessários para a especialização nesta função.

Além da relação temporal na abordagem dos conteúdos específicos, a divisão da formação em Educação Física entre Licenciatura e Bacharelado é apontada como um fator atenuante para suprir a demanda apresentada pelos treinadores em relação a esses conteúdos. Outros aspectos foram destacados pelos treinadores, como a falta de tempo hábil para o handebol (trecho 3) e a qualidade da mediação no ensino superior (trecho 4).

Trecho 3: "Você tem em um semestre só da modalidade ${ }^{53,54}$ ou dois ${ }^{57,511}$, e a maioria do pessoal nunca viu a modalidade na vida ${ }^{\$ 3}$. Tem que ensinar desde 0 básico, desde a história do esporte até dar aula da modalidade ${ }^{53}$. Não tem tempo hábil pra desenvolver toda a inteligência de jogo que você precisa, inteligência tática, aprender fundamentos ${ }^{S 1}$."

Trecho 4: "Alguns professores não eram capacitados, não tinham a formação no handebo| ${ }^{22,56}$, tinham pouco contato com o handebo|s6. Quando eu fiz a faculdade de Educação Física, sabia mais que meu professor ${ }^{56}$. Na nossa época falava-se muito pouco da Pedagogia do Esporte ${ }^{\mathrm{s2}}$. Parecia que o conteúdo ensinado não tinha sequência ${ }^{57 "}$. 
Verifica-se que há vários motivos para que a percepção sobre a influência da graduação no domínio dos conhecimentos necessários para ser um treinador sejam insuficientes, como a baixa carga horária destinada a cada esporte, a falta de experiências prévias com o handebol (trecho 3) e a capacitação dos docentes em relação ao handebol (trecho 4). Lemyre, Trudel e Durand-Bush (2007) apresentaram como fator limitante no contexto formal o pouco tempo de aprendizagem destinado a uma grande quantidade de conteúdos teóricos, panorama esse também referido no trecho 3 do DSC1.

Ainda no trecho 3 um dos destaques se refere à falta de experiência prévia no handebol pelos graduandos como atleta e/ou como treinador. A formação do treinador esportivo inicia-se muitas vezes antes do seu ingresso no ensino superior, e não somente na relação de espera pelo conhecimento advindo do docente para contemplar todas as possibilidades que permeiam a sua formação. Muitos dos treinadores entrevistados quando ingressaram na graduação já possuíam vivências como atletas de handebol, aspecto muitas vezes não observado por esses em seus companheiros de classe e nos próprios docentes que ministravam a disciplina específica. Esse aspecto corrobora Cunha, Estriga e Batista (2014), que apontaram que a vivência como atleta não parece ser um pré-requisito para o sucesso na carreira como treinador, mas para a aprendizagem dos conteúdos específicos do handebol, valorizando este passado como atleta ou as experiências com o jogo que tiveram ao longo da carreira.

Pelo fato de já possuírem experiências prévias no handebol, alguns dos entrevistados apontaram as críticas referentes à escassez de subsídios teóricos durante a graduação, principalmente ao comparar com as vivências dos próprios docentes (trecho 4). A qualidade da mediação apontada pelos entrevistados (trecho 4) é importante para o desenvolvimento do senso crítico em relação aos diferentes elementos que constituem o processo de ensino do handebol. Assim, o docente deveria ser o mediador de situações de aprendizagem, promovendo a reflexão sobre os assuntos pertinentes ao ensino e ao treinamento do handebol, configurando uma situação de mediação que permita a interação do conhecimento proveniente das suas vivências com aqueles advindos das vivências dos discentes (MILISTETD et al., 2015; STOSZKOWSKI; COLLINS, 2016).

Devido às suas características, somente o contexto formal não é suficiente para que os treinadores se aprofundem nos conteúdos necessários para sua atuação (WERTHNER; TRUDEL, 2006; MILISTETD et al., 2015), fator este que também se apoia no caráter generalista da estrutura curricular, fomentando a busca por outros contextos como o não formal, apresentado no DSC2 (proveniente da IC-2: "Me atualizo por meio de cursos", compartilhada por três treinadores):

Me aperfeiçoei com cursos e/ou minicursos de finais de semana ${ }^{s 11}$. Esses cursos têm desde assuntos específicos do esporte até arbitragem. Acho que ajuda o profissional atualmente para qualquer segmento ${ }^{59}$. Mas a maioria dos cursos você tem que procurar por fora, pois são muito poucos os que tem e normalmente são em São Paulo; assim chega muito pouco para nós ${ }^{\$ 3, S 11}$. O que falta no handebol são umas escolas de treinadores, que espero que se realizem ${ }^{\text {s11. }}$.

No DSC5 os treinadores entrevistados entendem que os cursos auxiliam no aperfeiçoamento da sua atuação profissional, diferenciando-se dos achados de Cunha, Estriga e Batista (2014), que entrevistaram treinadores de handebol da 1a divisão portuguesa e verificaram que tais cursos foram considerados pouco relevantes por serem de baixa qualidade 
e não apresentarem novidades. Uma possível diferença entre os achados dos autores e os entrevistados desta pesquisa pode ser explicada pelos contextos dos sujeitos: treinadores com amplas experiências e tempo de prática em Portugal versus treinadores em âmbito escolar, sendo alguns com pouca ou nenhuma experiência prévia no handebol.

No caso português, devido aos anos de experiência, o formato atual dos cursos propostos não atende à demanda de conhecimento que os treinadores daquele contexto necessitam e/ou esperam. No caso dos treinadores entrevistados, devido à pouca experiência e à formação acadêmica generalista, esses procuram cursos específicos para suprir lacunas de conhecimento. No entanto, os cursos deveriam ter maior especificidade, a partir da seleção de um determinado conteúdo para o público-alvo estudado.

Parece haver, portanto, uma relação estreita entre o tempo de prática e a valorização dos cursos específicos da modalidade, se aproximando dos achados de outros autores (CUNHA; ESTRIGA; BATISTA, 2014; TRUDEL et al., 2016). Trudel et al. (2016) apontam que a busca por situações de aprendizagem mediada ocorre com maior frequência nos anos iniciais da carreira como treinador e, ainda, se a experiência prévia como atleta for pequena ou inexistente (assim como verificado no trecho 3 do DSC1).

Outros problemas são apontados pelos treinadores no DSC2, como a escassez de cursos oferecidos e as distâncias para os locais onde são realizados. Tais fatores, juntamente com a temática oferecida nos cursos, constituem-se como limitadores para 0 acesso dos treinadores. Lemyre, Trudel e Durand-Bush (2007) argumentaram que muitos cursos formais de treinadores apresentam aspectos gerais, como fisiologia muscular e sistemas aeróbio/anaeróbio, congregando treinadores de diferentes esportes. No entanto, esses não valorizaram muito essas temáticas, e sim conteúdos relacionados às regras, aos sistemas táticos e aos fundamentos.

A partir dos contextos de aprendizagem formal e não formal percebe-se que muitas das estratégias mencionadas caracterizam-se como situações de aprendizagem mediada (CUNHA; ESTRIGA; BATISTA, 2014). Tais situações são importantes nesses contextos devido à organização e hierarquização de conteúdos no currículo, sendo papel do mediador construir o conhecimento com seus aprendizes.

Os treinadores destacaram outras possibilidades de desenvolver os conhecimentos específicos do handebol, aludindo ao contexto informal de aprendizagem, assim apresentadas: DSC3 (proveniente da IC-3: "Contato com outros treinadores", compartilhada por nove treinadores); DSC4 (proveniente da IC-4: "Busco diferentes materiais", compartilhada por oito treinadores); DSC5 (proveniente da IC-5: "Me baseio na minha experiência como atleta", compartilhada por sete treinadores).

Nesse contexto informal de aprendizagem a fonte mais citada pelos entrevistados se referiu às trocas de experiências com seus pares (DSC3), os quais reafirmam a fragilidade da graduação no domínio dos conteúdos específicos e apontam a importância do contato com os demais treinadores do mesmo âmbito.

A formação esportiva na modalidade foi mínima dentro do meu curso, o pouco embasamento que tenho hoje consegui fora das instituições, por meio do contato com o próprio pessoal do handebo| ${ }^{4,56}$, dos colegas da área que já conheço $\mathrm{e}$ vou perguntando, fazendo estágio com outros treinadores de handebo| $\left.\right|^{51, \$ 5, \$ 7, S 8}$ e assistindo jogos de outras equipes ${ }^{59}$. 0 objetivo é sempre compartilhar ideias novas para se atualizar no esporte, discutir como está a tendência do jogo, a 
velocidade ${ }^{\mathrm{S3}}$. O intercâmbio que fazemos com equipes mais fortes nos proporciona uma base muito boa; jogar com mais gente, com culturas diferentes, ajuda a observar o que serve para você e adaptar para a sua realidade ${ }^{s 10}$.

A aprendizagem, nesse caso, ocorre a partir da partilha de pensamentos, experiências, ideias, informações e recursos de um grupo de indivíduos que possuem diferentes vivências (embora em ambientes similares), bem como das experiências diárias e exposição ao meio ambiente, e que pode fornecer informações para solucionar problemas ou dilemas práticos do campo de atuação (NELSON; CUSHION; POTRAC, 2006).

Embora os entrevistados sejam rivais em diversas competições que ocorrem em âmbitos municipal, regional e estadual, nota-se no DSC3 que há partilha de informações, inclusive com observações de sessões de treinamentos, de jogos e com estágios com outros treinadores. Apesar do caráter competitivo entre os treinadores entrevistados, trata-se de um contexto diferente do analisado por Lemyre, Trudel e Durand-Bush (2007), que consideram as interações entre os treinadores rivais interessantes pelas experiências compartilhadas, mas o fato de competirem entre si torna a troca de informações pouco frequente por sentirem-se "ameaçados". Esse mesmo panorama foi relatado por Wright, Trudel e Culver (2007), no qual os treinadores não trocavam experiências com seus rivais em competições.

As boas interações com outros treinadores (DSC3) destacam a relevância das trocas de experiências entre os pares, abrangendo a construção de um conhecimento baseado no próprio ambiente de atuação, respeitando-se as limitações e as potencialidades de cada espaço. Portanto, muito do que um treinador novo aprende (como os aspectos técnicos e táticos do treinamento) se dá pelas interações no contexto prático, pautando-se nas interações com outros treinadores mais experientes durante treinos e jogos (CUSHION et al., 2003), assim como relatado no DSC3.

Além do contato com outros treinadores, os entrevistados apontaram outras fontes de conhecimento informal, como livros, vídeos e internet, conforme apresentado no DSC4:

\footnotetext{
Tenho procurado muitos vídeos na internet ${ }^{\$ 1,52, S 3,56,57,58}$ de esquema tático, de iniciação ${ }^{54,58}$, de equipes e treinadores de outras seleções para me manter atualizado ${ }^{56}$. Se eu não achar, recorro a teses, estudos ${ }^{57}$, alguns vídeos a gente passa para os alunos para que possam visualizar o que está falandos2. Alguns livros a gente consegue puxar; então consegue ler livros ou artigos que vão especificamente no que te interessa ${ }^{\$ 5}$, depois vídeos relacionados pra olhar na prática 0 que estou lendo ${ }^{54,55}$. Hoje a internet é um dos poucos meios em que você consegue ter um acesso fácilis3, engloba tudo ${ }^{\$ 5}$. Eu percebi de um ano, um ano e meio pra cá, o aumento na internet de artigos de handebol, específico da modalidade ${ }^{\$ 4}$. Busco livros ${ }^{51, S 2}$, revistas ${ }^{55}$, livros táticos para tentar entender esquemas $^{\mathrm{s2}}$, porém na literatura mesmo não acha tanta coisa ${ }^{\mathrm{S3}}$, a maioria é muito básico e não tem uma visualização boa. Tem escrita mas você não consegue visualizar o que se quer dizers8 e você não tem tanto material para buscars3.
}

No DSC4 nota-se maior preferência pelo material que pode ser acessado via internet, em detrimento do material impresso. Esse aspecto pode ser justificado pelo amplo acesso dos treinadores à internet, bem como da maior variedade de conteúdos que podem ser acessados por esse meio, tais como animações, vídeos de treinamentos e/ou jogos, artigos e versões digitais de livros. Tal preferência pela aprendizagem de forma ativa apresenta-se de maneira alternativa e contraditória às formas mais tradicionais de ensino, assim como já mencionado por Wright, Trudel e Culver (2007). 
Cunha, Estriga e Batista (2014) apontam que as fontes buscadas no contexto informal são úteis por promoverem a informação, mas não preenchem todas as necessidades dos treinadores. Não obstante, não se pode pensar que somente tais fontes vão suprir as demandas para a formação do treinador, principalmente pela necessidade de uma formação que considere seu envolvimento com seu complexo contexto de atuação (BOWES; JONES, 2006; CASSIDY; JONES; POTRAC, 2009). As fontes mencionadas são pautadas nos interesses particulares dos treinadores (assim como as relações que estabelecem com seus pares), que possibilita dedicar sua atenção a temas específicos para aprendizagem. Ressalta-se, ainda, que os conteúdos buscados pelos treinadores podem ser diferentes, seja em quantidade ou em profundidade, de acordo com o nível de experiência e/ou conhecimento/experiências prévios. Ao se considerar tais experiências, os treinadores aludiram à influência dessas para o aperfeiçoamento dos conteúdos específicos do handebol, conforme apresentado no DSC5:

Joguei handebol há muitos anos ${ }^{54,57} \mathrm{e}$ existem coisas que você vai aprendendo com a prática, no dia a dia. A experiência faz uma grande diferenç̧a ${ }^{S 1, S 3}$ : se você não tem experiência prévia do esporte ${ }^{51,33,54}$, somente a graduação não será suficiente para se tornar treinador ${ }^{51,57}$. A minha formação era mais ou menos em cima daquilo que vivenciei como atleta ${ }^{54}$. Atualmente, além desse conhecimento, a vivência com as turmas escolares é importante ${ }^{511}$. A ida em uma competição interna ou externa à escola, o convívio com o próprio grupo, é um curso que eu faço durante todos os jogos. A gente aprende jogandos9, 510 .

O posicionamento dos treinadores no DSC5 destaca a relevância da experiência como atleta e das situações cotidianas para o domínio dos conteúdos específicos do handebol. Vale ressaltar que é necessário transcender as questões que envolvem apenas o ensino do gestual específico do handebol (MENEZES; REIS; MORATO, 2016) pela reprodução dos conhecimentos adquiridos enquanto atletas, o que não é suficiente para a compreensão da complexidade dos jogos (WERTHNER; TRUDEL, 2006; MENEZES, 2012).

Outro aspecto que merece destaque é que a formação de treinadores não perpassa apenas pelo nível competitivo de sua carreira enquanto atleta. Entendemos desta forma pois parte dos entrevistados não possuía experiências como jogadores de handebol e mesmo os poucos que haviam praticado o handebol em âmbitos mais competitivos estão igualmente contribuindo para a formação dos jovens.

Assim, as experiências enquanto atleta podem fazer com que o treinador possa ter um repertório maior para soluções específicas ao contexto do handebol. Embora este seja um fator que dependa da qualidade dos estímulos nos treinos aos quais foram submetidos, essa não é uma temática central para esta pesquisa. No contexto esportivo, em específico ao âmbito dos entrevistados, tais experiências podem subsidiar a tomada de decisão desses diante dos fatores imprevisíveis do jogo e, para isso, é necessário que o treinador tenha um papel ativo em sua aprendizagem (WERTHNER; TRUDEL, 2006).

Os diferentes ambientes mencionados no DSC5 (convívio com o próprio grupo, participação em competições internas e externas à escola, aprender jogando) constituem as "Comunidades de Prática do Coaching", definidas como um grupo de treinadores que partilham de interesses comuns relacionados a um assunto, problemas semelhantes e aprimoram o seu conhecimento ao interagir com outros protagonistas (JONES, 2006; CASSIDY; JONES; POTRAC; 2009). Nesse sentido destacamos o DSC3, o DSC4 e o DSC5, que tratam das interações entre os treinadores e os demais protagonistas e a importância dada a cada fonte de troca de experiências. 
Diante do contexto de aprendizagem informal, as estratégias utilizadas pelos treinadores caracterizam-se como situações de aprendizagem direta, pelo fato desses buscarem um conhecimento específico sem que, necessariamente, haja mediação por alguém mais experiente (CUNHA; ESTRIGA; BATISTA, 2014). Essas situações mostraram-se relevantes nesse contexto por pautarem-se na busca por conhecimentos sobre temas de preferência e/ou de fragilidade dos treinadores (DSC3, DSC4 e DSC5). Stoszkowski e Collins (2016) salientam que a percepção do seu próprio conhecimento atual influencia nos tipos de conhecimentos que os treinadores buscarão para melhorar as suas decisões.

As situações de aprendizagem mediada e direta, em todos os contextos, mostraramse importantes e indicam possíveis respaldos para a aprendizagem interna (reflexão sobre as informações e as experiências provenientes das diferentes fontes) (WERTHNER; TRUDEL, 2006; CUNHA; ESTRIGA; BATISTA, 2014).

A atuação dos treinadores se dá, portanto, em um contexto complexo, motivo pelo qual sua formação deva ser pautada em diferentes contextos de aprendizagem. Para Bowes e Jones (2006), a melhor maneira de entender o processo de formação de treinadores é considerá-lo multifacetado, dinâmico e que contemple as interações sociais que permeiam sua atuação. Nesse sentido, compreender os contextos e as situações nas quais os treinadores buscam o conhecimento é de extrema importância para as Ciências do Esporte, em especial para a compreensão de seu cenário de atuação e de possibilidades pedagógicas que fomentem trocas de experiências.

\section{CONSIDERAÇÕES FINAIS}

O objetivo desta pesquisa foi analisar a formação de treinadores de handebol de âmbito escolar de um município do Estado de São Paulo. As entrevistas evidenciaram a importância da formação generalista da graduação em Educação Física. Porém, a partir de diversas considerações sobre o que esperam para a atuação como treinador esportivo, principalmente em relação ao domínio dos conhecimentos específicos e à organização curricular dos cursos superiores, apenas o contexto formal não se mostrou satisfatório. Sugere-se maior aproximação entre a graduação e o campo prático, possibilitando amplas vivências em estágios em diferentes esportes.

Pautando-se nas necessidades do ambiente de atuação dos treinadores, verificou-se que esses recorreram a diferentes fontes nos contextos não formal (também consideradas insuficientes e escassas) e informal, como as experiências como atletas, as fontes diversificadas relacionadas à internet (justificada pela praticidade e interatividade) e a vivência/contato diário com suas equipes e outros protagonistas. $O$ contato com outros treinadores mostrou-se como uma das fontes preferidas pelos entrevistados, principalmente pelas possibilidades de trocas de experiências mesmo com treinadores adversários. Considera-se, então, que a atuação do treinador se dá em um ambiente complexo, e que, ao longo de sua experiência profissional, diferentes questões possam surgir, para as quais podem ser buscados diferentes contextos.

Destaca-se, também, a importância da proposta de análise da formação de treinadores de handebol de âmbito escolar, uma vez que permite revelar um campo ainda pouco explorado e, posteriormente, identificar aspectos que possam ser apropriados por cursos superiores de Educação Física para maior aproximação com a realidade enfrentada pelos futuros treinadores. 
De maneira análoga, espera-se ampliar a discussão para os treinadores que atuam no âmbito da iniciação esportiva, por se tratar da etapa na qual é exigida deles uma série de conhecimentos para o desenvolvimento dos jogadores.

Espera-se que o contato com os diferentes protagonistas (atletas, pais, arbitragem, gestores, torcedores, entre outros) nas situações e nos contextos relatados (formal, não formal e informal) possa influenciar as decisões e a percepção dos treinadores sobre o que consideram relevante para a aprendizagem. Tal fato requer um papel ativo sobre sua formação, em especial para as temáticas que englobam equipes em âmbito escolar, de modo que amplie o repertório de soluções específicas ao seu contexto.

Uma limitação deste estudo decorre da compreensão dos treinadores de âmbito escolar de um município do Estado de São Paulo e seus resultados podem não ser generalizáveis para outras regiões do estado ou do país, principalmente pela forma de organização das competições e dos espaços para o treinamento das equipes.

Por outro lado, a partir da compreensão dos aspectos levantados nesta pesquisa, tornase possível investir na qualidade das fontes buscadas pelos treinadores para melhorar sua atuação profissional. Apresenta-se como uma perspectiva futura de investigação o entendimento das razões que levam os treinadores a optarem por determinado tipo de conhecimento e/ou situação de aprendizagem, bem como os estudos com treinadores de outros âmbitos.

\section{REFERÊNCIAS}

BOWES, Imornefe; JONES, Robyn Lloyd. Working at the Edge of Chaos: Understanding Coaching as a Complex, Interpersonal System. The Sport Psychologist, v.20, 235-245, 2006.

BRASIL. Lei no 9615, de 24 de março de 1998. Institui normas gerais sobre desporto e dá outras providências. Diário Oficial da República Federativa do Brasil, Brasília, DF, 25 mar. 1998a. Disponível em: <http://www.planalto.gov.br/ccivil 03/leis/L9615consol.htm>. Acesso em: 22 jan. 2017.

BRASIL. Lei no 9.696, de 1․ de setembro de 1998. Dispõe sobre a regulamentação da Profissão de Educação Física e cria os respectivos Conselho Federal e Conselhos Regionais de Educação Física. Diário Oficial da República Federativa do Brasil, Brasília, DF, 2 set. 1998b . Disponível em:<http://www.planalto.gov.br/ccivil 03/leis//9696.htm>. Acesso em: 22 jan. 2017.

BRASIL. Resolução CNE/CP 1/2002, de 18 de fevereiro de 2002. Institui Diretrizes Curriculares Nacionais para a Formação de Professores da Educação Básica, em nível superior, curso de licenciatura, de graduação plena. Diário Oficial da República Federativa do Brasil, Brasília, DF, 9 abr. 2002. Seção 1, p.31. Republicada por ter saído com incorreção do original no D.O.U. de 4 mar. 2002. Seção 1, p.8. Disponível em: <http://portal.mec.gov.br/cne/arquivos/pdf/rcp01 02. pdf>. Acesso em: 22 jan. 2017.

BRASIL. Resolução CNE/CES 7/2004, de 31 de março de 2004. Institui as Diretrizes Curriculares Nacionais para os cursos de graduação em Educação Física, em nível superior de graduação plena. Diário Oficial da República Federativa do Brasil, Brasília, DF, 5 abr. 2004, Seção 1, p.18. Disponível em: <http://portal.mec.gov.br/cne/arquivos/pdf/ces0704edfisica.pdf>. Acesso em: 22 jan. 2017. 
CASSIDY, Tania; JONES, Robyn Lloyd; POTRAC, Paul. Understanding sports coaching: the social, cultural and pedagogical foundations of coaching practice. 2.ed. Oxon: Routledge, 2009.

CUNHA, Ana Filipa Vasquez Paulo; ESTRIGA, Maria Luisa Dias; BATISTA, Paula Maria Fazendeiro. Fontes de conhecimento percebidas pelos treinadores: estudo com treinadores de andebol da $1^{\underline{a}}$ divisão de seniores masculinos em Portugal. Movimento, v.20, n.3, p.917-940, 2014.

CUSHION, Christopher J.; ARMOUR, Kathy M.; JONES, Robyn L. Coach education and continuing professional development: Experience and learning to coach. Quest, v.55, n.3, p.215-230, 2003.

FEU MOLINA, Sebastián; IBÁÑEZ GODOY, Sergio José; GOZALO DELGADO, Margarita. La formación inicial de los entrenadores de balonmano para la enseñanza del deporte en la edad escolar. Cultura, Ciência e Deporte, v.5, n.14, p.109-117, 2010.

FLICK, Uwe. Introdução à pesquisa qualitativa. 3.ed.: Porto Alegre: Artmed, 2009.

GALATTI, Larissa Rafaela et al. Coaches' perceptions of youth players' development in a professional soccer club in Brazil: paradoxes between the game and those who play. Sports Coaching Review, v.5, n.2, p.174-185, 2016.

JONES, Robyn Lloyd. How can educational concepts inform sports coaching? In: Jones, $R$. (Ed.). The sports coach as educator: re-conceptualising sports coaching. New York: Routledge, 2006. p. 3-13.

LEFÈVRE, Fernando; LEFÈVRE, Ana Maria Cavalcanti. Pesquisa de representação social: um enfoque qualiquantitativo. 2. ed. Brasília: Liber Livro, 2012.

LEMYRE, François; TRUDEL, Pierre; DURAND-BUSH, Natalie. How Youth-Sport Coaches Learn to Coach. The Sport Psychologist, v.21, p.191-209, 2007.

MARCONI, Marina de Andrade; LAKATOS, Eva Maria. Metodologia científica. 6.ed. São Paulo: Atlas, 2011.

MARQUES, Renato Francisco Rodrigues. O conceito de esporte como fenômeno globalizado: pluralidade e controvérsias. Revista Observatorio del Deporte, v.1, n.1, p.147-185, 2015.

MENEZES, Rafael Pombo. Contribuições da concepção dos fenômenos complexos para o ensino dos esportes coletivos. Motriz, v.18 n.1, p.34-41, 2012.

MENEZES, Rafael Pombo; REIS, Heloisa Helena Baldy dos; MORATO, Márcio Pereira. O handebol, seu cenário imprevisível e os métodos de ensino-aprendizagem-treinamento. e-balonmano.com: Revista de Ciencias del Deporte, v.12, n.3, p.165-176, 2016.

MILISTETD, Michel et al. Coaching and Coach Education in Brazil. International Sport Coaching Journal, v.1, p.165-172, 2014.

MILISTETD, Michel et al. A aprendizagem profissional de treinadores esportivos: desafios da formação inicial universitária em Educação Física. Pensar a Prática, v.18, n.4, p.982-994, 2015.

NELSON, Lee J.; CUSHION, Christopher J.; POTRAC, Paul. Formal, nonformal and informal coach learning: a holistic conceptualisation. International Journal of Sports Science \& Coaching, v.1, n.3, p.247-259, 2006.

STOSZKOWSKI, John; COLLINS, Dave. Sources, topics and use of knowledge by coaches. Journal of Sports Sciences, v.34, n.9, p.794-802, 2016. 
THOMAS, Jerry R.; NELSON, Jack K.; SILVERMAN, Stephen J. Métodos de pesquisa em atividade física. 6.ed. Porto Alegre: Artmed, 2012.

TRUDEL, Pierre; GILBERT, Wade; RODRIGUE, François. The journey from competent to innovator: using appreciative inquiry to enhance high performance coaching. International Journal of Appreciative Inquiry, v.18, n.2, p.40-46, 2016.

WERTHNER, Penny; TRUDEL, Pierre. A new theoretical perspective for understanding how coaches learn to coach. Sport Psychologist, v.20, n.2, p.198-212, 2006.

WRIGHT, Trevor; TRUDEL, Pierre; CULVER, Diane. Learning how to coach: the different learning situations reported by youth ice hockey coaches. Physical Education and Sport Pedagogy, v.12, n.3, p.127-144, 2007. 